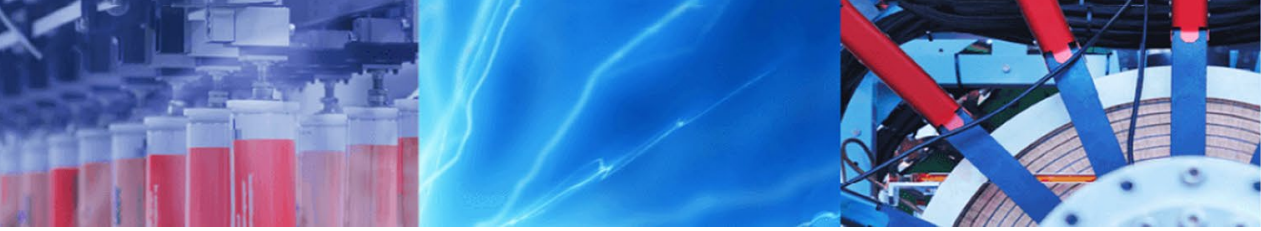

Research Article

\title{
Influence of variable inertia flywheel and soft switching on a power hydraulic system
}

\author{
Anil C. Mahato ${ }^{1} \cdot$ Sanjoy K. Ghoshal ${ }^{2} \cdot$ Arun K. Samantaray $^{1}$
}

(c) Springer Nature Switzerland AG 2019

\begin{abstract}
In this work a variable inertia flywheel and a soft switch are incorporated into an on/off valve-controlled power hydraulic system to analyze the influences of those in energy saving and vibration isolation of the system. Four different configurations of hydrostatic transmission systems, i.e. Hydrostatic Transmission with Constant Inertia Flywheel (HST CIF $_{\text {) }}$, Hydrostatic Transmission with Variable Inertia Flywheel (HST VIF), Hydrostatic Transmission with Constant Inertia Flywheel and Soft

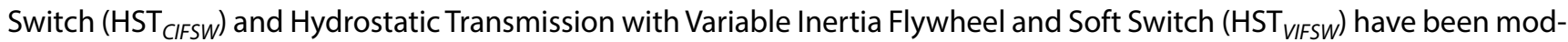
eled and simulated. The Lagrange's approach is used to obtain the mathematical model of the variable inertia flywheel. The main objective of the study is to reduce the transient peak of the system response by using the variable inertia flywheel and the soft switch individually or collectively. It is observed that the incorporation of these two components together provides benefits from two different perspectives, i.e. energy savings and vibration reduction of the system.
\end{abstract}

Keywords Variable inertia flywheel · Soft switch · Lagrange's approach · Passive vibration isolation · Throttling energy loss

\section{Introduction}

Most hydraulic machines are subject to time-varying forces which produce time-dependent motions of the system. The acceleration/deceleration of mass causes inertia force that works against the compliance of the body, leading to restoring forces. Thus, under the action of the external disturbances, the inertia and the restoring internal forces on the body cause unwanted vibration, which can be torsional, linear or bending vibration, depending upon the machine configuration. Vibration in any mechanical system is a serious issue which may affect the machine lifespan, product quality, safety, etc. Besides, it may generate structural noise [1]. Therefore, reduction and control of vibration is an important task. The basic elements for any vibratory systems are spring, mass and damper. The effective design, optimization and precise fabrication of these three elements are important towards the design of an effective vibration isolation system $[2,3]$.

Two different methods can be used to control the vibration of the system, i.e. active and passive control $[4,5]$. Active vibration control (AVC) system reacts dynamically to the incoming vibration that means it senses incoming vibrations and then reacts on it. AVC system contains one feedback circuit which consists of sensors, transducers (electromagnetic), controllers and actuators. An AVC system where piezoelectric stack actuators are installed on a flexible horizontal rotor and a modal control strategy is applied is presented in [6]. Another AVC strategy has been introduced by in [7] where an active suspension system has been designed using a PID controller to enhance the ride comfort and road holding capability of the system. Currently, researchers have focused towards semi-active vibration control system by designing variable stiffness and damping of the system $[8,9]$. AVC is suitable for

Sanjoy K. Ghoshal, sanjoykghoshal@iitism.ac.in | 'Department of Mechanical Engineering, Indian Institute of Technology, Kharagpur 721302, India. ${ }^{2}$ Department of Mechanical Engineering, Indian Institute of Technology (ISM), Dhanbad 826004, India.

SN Applied Sciences (2019) 1:605 | https://doi.org/10.1007/s42452-019-0623-0 
low-level vibration (low frequency) system. It is a complex system and costlier. On the other hand, Passive Vibration Control (PVC) system refers to shock relief without using any external power. Usually, passive isolation system contains mass, spring, and damping elements. It is simple in design and effectively used in high frequency vibration isolation [10], but has limited bandwidth in which vibration isolation is achieved.

Previously, researchers had adopted multiple approaches for passive vibration control (PVC). For example, Tuned Mass Damper (TMD) [11, 12], inerter [13, 14], spiral flywheel [15], screw-based two-terminal flywheel $[16,17]$, electro-hydraulic variable two-terminal mass device [18] etc. TMD is a dynamic vibration absorber which controls the natural frequency of the system to suppress the vibration of the system by incorporating an additional mass into the system. The additional mass increases the inertia of the flywheel and needs increased stiffness and damping in the system [11, 12]. Another PVC concept is inerter which is a two-terminal based device and is similar to an electrical capacitor. It is simple to realize and eliminates the need for additional mass [13, 14]. Similarly, a motion conversion system has been developed in [15] by considering a spiral flywheel in a vibratory system. In $[16,17]$, a two-terminal screw-based flywheel approach is developed where a relative linear motion between two terminals for a mass component is established to adopt the inverse translation of the screw, and the rotation of the flywheel and relative translation between two terminals are controlled by a proportional valve such that the equivalent inertial mass of the device is adjustable. Additionally, an electro-hydraulic variable two-terminal mass device has been introduced in [18]. In that approach, the flywheel is mounted between two terminals of a hydraulic cylinder which is controlled by a hydraulic system. Most of the published vibration isolation concepts generate a constant equivalent mass, whereas a very few deal with variable equivalent mass. To increase the bandwidth or frequency range of vibration isolation, recently, some researchers have proposed the use of flywheel with variable inertia [19, 20]. In [21], a promising design of the variable inertia flywheel, which is composed by a circular plate design with four slots, four sliders, four springs and two circular covers, is introduced. The primary objective in [21] was to generate variable equivalent mass tuned to variable input excitation, and thus, a two-terminal hydraulic system was considered therein for performance analysis and experimental validation.

Vibration reduces the useful mechanical energy of the system by dissipating it as heat or other forms of irrecoverable energy. Therefore, the energy efficiency of the system reduces when there is severe vibration. In hydraulic control systems, it is observed that the vibration control system prevents the pressure surge under large transient events. Similar phenomenon can be seen when a soft switch [22-26] is used in an on/off valve control hydraulic system. Soft switch is a device used to provide a temporary flow path of the high pressure throttled fluid whenever the controlled valve is in transition mode. The soft switch reduces the pressure surge of the system and reduces the energy loss from the system. In the available literature, whether in addition to pressure surge reduction, the soft switch plays any role to reduce the vibration of the system has not been investigated. Likewise, whether in addition to vibration reduction, the variable inertia flywheel (VIF) plays any role in energy saving has not been investigated. Needless to mention, the combined effect of these devices is not assessed so far.

This article provides a comparative study between the constant inertia flywheel (CIF), the variable inertia flywheel and the soft switch to analyze the influence of both the devices in a switched mode power hydraulic system. Also, it quantifies the contribution of the variable inertia flywheel and the soft switch regarding passive vibration isolation and energy saving. This work accounts for the Coriolis forces on the slider of the variable inertia flywheel which has been ignored in the previous studies. Four different configurations of a switch mode hydraulic system i.e. Hydrostatic Transmission with Constant Inertia Flywheel $\left(\mathrm{HST}_{C I F}\right)$, Hydrostatic Transmission with Variable Inertia Flywheel (HST VIF), Hydrostatic Transmission with Constant Inertia Flywheel and Soft Switch (HST CIFSW $_{\text {) }}$ and Hydrostatic Transmission with both Variable Inertia Flywheel and Soft Switch (HST VIFSW), have been analyzed through numerical simulations.

\section{Working principle}

The circuit diagram of an on/off high-speed valve-controlled power hydraulic system with the flywheel and soft switch considered for the present study is shown in Fig. 1. The hydraulic pump (item no. 2) is used as constant flow $\left(Q_{\text {pump }}\right)$ supply equipment and it is driven by an electric motor (item no. 1). The pump flow passes through a 4/2 Directional Control Valve (DCV) (item no. 3). The function of the DCV is to control the system flow through Pulse Width Modulated (PWM) input. The flow from the DCV drives the hydraulic gerotor motor (item no. 4). The flywheel (item no. 5) is coupled to the hydraulic motor shaft. This flywheel is either of constant inertia flywheel (CIF) or of variable inertia flywheel (VIF). The VIF is composed of a circular plate which has four slots, four sliders and four compression springs. The detailed operation of the variable inertial flywheel is available in [20]. Besides, the soft switch (item no. 6) is a mechanical 
1. Electric motor

2. Hydraulic

3. $4 / 2 \mathrm{DCV}$

4. Hydraulic motor

5. Flywheel

6. Soft switch

7. Tank

8. Check valve

9. Radial piston pump

10. Loading valve (PRV)
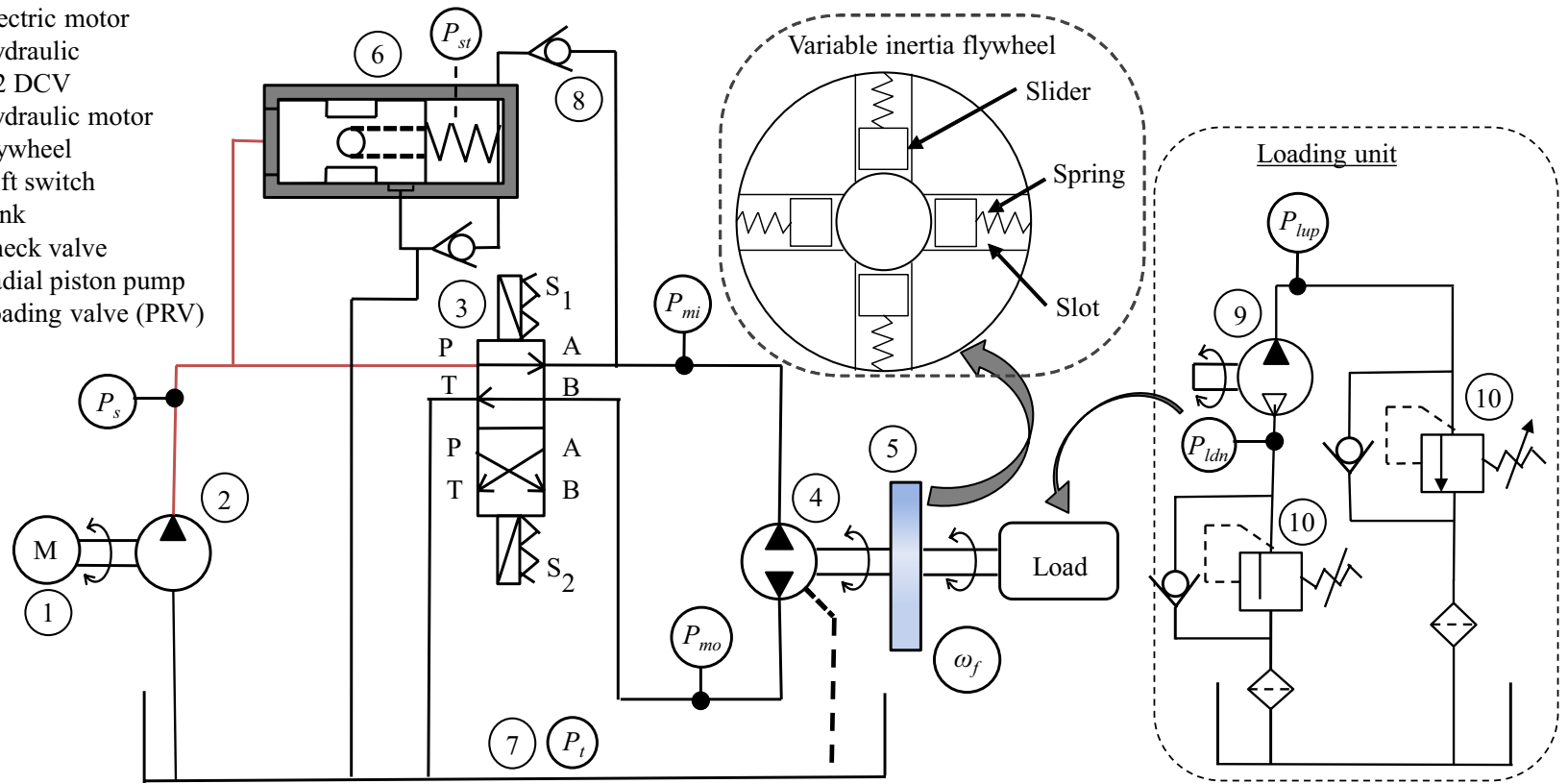

Fig. 1 An on/off high-speed valve controlled power hydraulic system with flywheel and soft switch

device used to temporarily store high pressure fluid throttled into it during valve transition [22-26] and it is connected between the hydraulic pump and the DCV. Two check valves (item no. 8) are connected to the soft switch to perform the desired unidirectional operation and also, for safety purpose. The basic operating principle of the soft switch is available in [22-26].

Initially, this study focuses on analysis of the influence of the VIF and the soft switch on a 4/2 DCV controlled hydraulic system during the transition of the valve without any additional loading unit. Later on, the loading unit is introduced in the analysis. An enlarged view of the loading unit is shown in Fig. 1 and the results pertaining to the effect on the system pressures $\left(P_{m i}\right.$ and $P_{m o}$ ) due variable loading conditions are discussed later in Sect. 5.1. In the loading unit, the shaft of the radial piston pump (item no. 9) is coupled with the same shaft of the flywheel and the hydro motor. Two relief valves (item no. 10) are used to produce the load variation in the circuit by varying its set pressure $\left(P_{\text {set }}\right)[26,27]$.

The sequences of the DCV ports (normal port and cross port) opening and closing (port opening areas) are shown in Fig. 2. During starting of the test, $S_{1}$ solenoid (see Fig. 1) is energized and flow passes through the normal port. After a certain period of operation (11.5 s), $\mathrm{S}_{1}$ solenoid is de-energized and $\mathrm{S}_{2}$ solenoid is energized, i.e. the normal port of the valve is closed and the crossed port is opened. In the next subsequence $(20 \mathrm{~s}), \mathrm{S}_{2}$ solenoid is de-energized and $S_{1}$ is energized. This process continues in a loop.

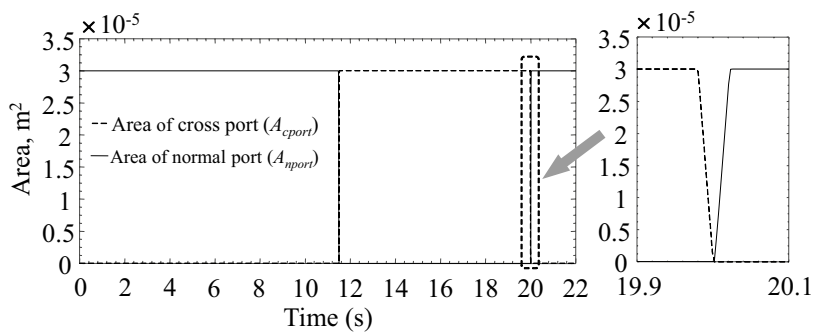

Fig. 2 Variation in the orifice area of normal and cross port of the $4 / 2$ DCV versus time

\section{Modelling of the hydraulic system}

The assumptions, which are considered in the model development and simulation, are given below:

1. The working fluid inertia is negligible.

2. Valve dynamics is not considered, valves are fast acting.

3. Fluid properties are unaltered with the variation of temperature, if any.

4. Internal dynamics of the hydraulic pump are not addressed and it is used as constant flow supply equipment.

In this section, the performances of the two systems, i.e. $\mathrm{HST}_{C I F}$ and $\mathrm{HST}_{V I F}$, are compared, while the soft switch and the loading circuit are not considered. Thereafter, 
the soft switch has been incorporated and the flywheel inertia is changed from its fixed structure to a nonlinear variable structure in two configurations, i.e. HST $_{\text {CIFSW }}$ and HST $_{\text {VIFSW }}$. Among the four different stated configurations, HST $_{C I F}$ is the base model, which corresponds to the raw system without any additional features (VIF and soft switch). Its modeling is discussed in the next subsection.

\subsection{Modeling of hydrostatic transmission with constant inertia flywheel (HST IIF )}

The hydraulic pump is a fixed displacement pump and it always maintains a constant flow supply $\left(Q_{\text {pump }}\right)$. The pressure developed at the pump plenum $\left(P_{s}\right)$ is obtained from the definition of the bulk modulus of the working fluid and it is written as

$\dot{P}_{s}=\frac{B_{e f}\left(P_{s}\right)}{V_{s w}+A_{s s} y_{s s}}\left(Q_{\text {pump }}-Q_{n p o r t}-Q_{c p o r t}-A_{s s} v_{s s}\right)$,

where $V_{s w}$ is the switched fluid volume including the line volume; $A_{s s}=\pi d_{s s}^{2} / 4, y_{s s}$ and $v_{s s}=\dot{y}_{s s}$ are the effective surface area of the piston, travel distance of the piston and its instantaneous velocity in the soft switch, respectively, $d_{s s}$ is the diameter of soft switch piston, $Q_{n p o r t}$ and $Q_{c p o r t}$ are the volume flow rate into the plenum through normal and cross ports, respectively, and $B_{\text {ef }}$ is the effective bulk modulus of the working fluid. $B_{e f}$ is given as a function of the system pressure [28], i.e.

$B_{e f}(P)=B\left[\frac{\left(P / P_{0}\right)\left(\frac{1}{\gamma}\right) e^{\frac{\left(P-P_{0}\right)}{B}}+X}{\frac{X B}{\gamma P}+\left(P / P_{0}\right)\left(\frac{1}{\gamma}\right) e^{\frac{\left(P-P_{0}\right)}{B}}}\right]$,

where the bulk modulus of air-free flowing fluid is denoted by $B, P_{0}$ is the atmospheric pressure, $\gamma=1.4$ and $X=0.02$ are the adiabatic constant and volume fraction of air entrained in the fluid, respectively. The soft switch terms $\left(A_{s s}, y_{s s}\right.$ and $\left.v_{s s}\right)$ are eliminated from Eq. (1) whenever soft switch is absent from the circuit.

The flow through the $4 / 2$ switched solenoid DCV, i.e. $Q_{\text {nport }}$ through the normal port and $Q_{c p o r t}$ through the cross port, are non-linear. At any time, one port is open and the other is closed. These flows are given as

$Q_{\text {nport }}=C_{d} A_{\text {nport }}(t) \sqrt{\frac{2\left(P_{s}-P_{m i}\right)}{\rho}}$
$Q_{\text {cport }}=C_{d} A_{\text {cport }}(t) \sqrt{\frac{2\left(P_{s}-P_{m o}\right)}{\rho}}$, where $C_{d}$ is the co-efficient of discharge, $A_{\text {nport }}(t)$ and $A_{\text {cport }}(t)$ are the time-varying port opening areas of the DCV as shown in Fig. $2, \rho=870 \mathrm{~kg} \mathrm{~m}^{-3}$ is the mass density of the hydraulic fluid, and $P_{m i}$ and $P_{m o}$ are the pressures in hydro-motor plenums as shown in Fig. 1.

The pressure at the hydro-motor plenums are computed from the first order coupled differential equations

$$
\begin{aligned}
\dot{P}_{m i}= & \frac{B_{e f}\left(P_{m i}\right)}{V_{m i}}\left(Q_{n p o r t}+Q_{s c h v}-D_{m} \omega_{f}-P_{m i} / R_{\text {leak }}\right. \\
& \left.-\left(P_{m i}-P_{m o}\right) / R_{i l}-Q_{c p o r t r}\right), \\
\dot{P}_{m o}= & \frac{B_{e f}\left(P_{m o}\right)}{V_{m o}}\left(Q_{c p o r t}+D_{m} \omega_{f}-P_{m o} / R_{\text {leak }}\right. \\
& \left.+\left(P_{m i}-P_{m o}\right) / R_{i l}-Q_{\text {nportr }}\right),
\end{aligned}
$$

where $V_{m i}=V_{m o}=V_{m}$ represents the fixed line volume in pump plenum by including the average effective volume of gerotor lobes, $D_{m}$ and $\omega_{f}$ are the volume displacement rate of the hydro-motor and rotational speed of the flywheel, respectively, $R_{i j}$ is the internal leakage resistance at hydro-motor plenum, $R_{\text {leak }}$ is the external leakage resistance, $Q_{\text {nportr }}$ and $Q_{\text {cportr }}$ are the return flows through the DCV from hydro-motor to the tank in normal and cross port configurations, respectively, and $Q_{\text {schv }}$ is the flow through the safety check valve of the soft switch as described later in Sect. 3.3. The return flows through the DCV from hydro-motor to the tank are given as

$Q_{n \text { portr }}=C_{d r} A_{\text {nport }}(t) \sqrt{\frac{2\left(P_{m i}-P_{t}\right)}{\rho}}$
$Q_{c \text { portr }}=C_{d r} A_{c p o r t}(t) \sqrt{\frac{2\left(P_{m o}-P_{t}\right)}{\rho}}$,

where $C_{d r}=C_{d}$ is the discharge co-efficient, $P_{t}$ is the tank pressure which is equal to the atmospheric pressure $\left(P_{0}\right)$, and $A_{\text {nport }}(t)$ and $A_{\text {cport }}(t)$ are the time-varying port opening areas of the DCV as shown in Fig. 2.

The speed of the flywheel $\left(\omega_{f}\right)$ is obtained by integrating the inertia torque load equation of the flywheel, i.e.

$\dot{\omega}_{f}=\frac{D_{m}\left(P_{m i}-P_{m o}\right)-c_{\text {line }} \omega_{f}-c_{\theta} \omega_{f}-D_{p}\left(P_{\text {lup }}-P_{\text {ldn }}\right)}{J_{f}}$,

where $c_{\text {line, }} c_{\theta}$ and $J_{f}$ are the line resistance of the circuit, the viscous frictional coefficient of the flywheel, and the moment of inertia of the flywheel, respectively, $P_{\text {lup }}$ and $P_{\text {Idn }}$ are the pressures in the loading system (see Fig. 1), and $D_{p}$ is load pump's volume displacement rate. Equation (6) will 
be revised for variable inertia flywheel. When load pump is disconnected, $D_{p}=0$ is used.

\subsection{Modeling of variable inertia flywheel}

In variable inertia flywheel, the inertia of the flywheel varies due to the movement of the slider through the slot. The schematic diagram of the variable inertial flywheel is shown in Fig. 3. The springs are initially at their free-length in the extended position touching the hub when the flywheel speed is zero. The effect of gravity is neglected here. The springs cannot extend further, but can only come under compression.

The moment of inertia of the slider abouts its own mass center and that of the fixed structural part about the shaft center, respectively, are expressed as

$J_{s}=\frac{1}{4} m_{s}\left(\frac{d_{s}^{2}}{4}+\frac{l_{s}^{2}}{3}\right)$

$J_{f}=J_{\text {shaft }}+J_{s c d}-N_{s} J_{\text {slot }}$,

where $m_{s}, d_{s}, l_{s}$ and $N_{s}=4$ are the slider mass, slider diameter, slider length and number of slots, respectively, $J_{s c d}=\frac{1}{2} m_{s c d}\left(r_{i}^{2}+r_{o}^{2}\right)$ is the polar moment of inertia of a solid flywheel of uniform thickness, $m_{s c d}$ is its mass, $J_{\text {shaft }}$ is the polar moment of inertia of the shaft, and $r_{i}$ and $r_{o}$ are the inner and outer radius of the circular disk, respectively, and the lost inertia of the removed material from each rectangular slot

$J_{\text {slot }}=m_{\text {slot }}\left\{\frac{1}{12}\left(d_{s}^{2}+l_{\text {slot }}^{2}\right)+\left(r_{o}-0.5 l_{\text {slot }}\right)^{2}\right\}$,

where $m_{\text {slot }}$ and $l_{\text {slot }}$ are the mass of the removed material from each slot of the circular disk and the length of the slot, respectively.

The slider moves along the slot while it rotates along with the flywheel. The equation of the motion of the slider can be obtained using Lagrange's approach [29-32]. The Lagrangian is expressed as

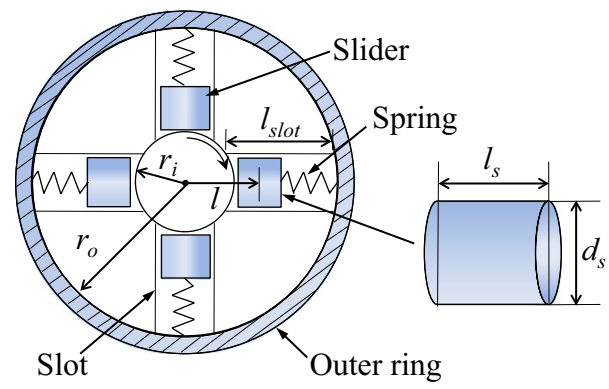

Fig. 3 Schematic representation of variable inertia flywheel
$L=T-U$

where $T$ and $U$ are the kinetic and potential energy of the variable inertial flywheel, respectively. The kinetic energy can be formulated from radial and tangential velocity components of the $i$ th slider, $\dot{l}_{i}$ and $l_{i} \dot{\theta}$, respectively, as

$T=\frac{1}{2} \sum_{i=1}^{4} m_{s}\left(\dot{l}_{i}^{2}+l_{i}^{2} \dot{\theta}^{2}\right)+\frac{1}{2}\left(J_{f}+4 J_{s}\right) \dot{\theta}^{2}$,

where $\dot{l}_{i}$ and $\dot{\theta}=\omega_{f}$ are the instantaneous linear velocity of the ith $(i=1.0 .4)$ slider and angular velocity of the flywheel, respectively, and $J_{f}$ is the polar moment of inertia of the flywheel given in Eq. (8).

The potential energy $U$ of the slider, neglecting the gravity, and the Rayleigh dissipation function $D$ for resistive losses are introduced as

$U=\frac{1}{2} \sum_{i=1}^{4} k_{f s}\left(I_{i}-I_{\min }\right)^{2}$ and $D=\frac{1}{2} c_{\theta} \dot{\theta}^{2}+\frac{1}{2} c_{\text {line }} \dot{\theta}^{2}+\frac{1}{2} \sum_{i=1}^{4} c_{i} I_{i}^{2}$

where $k_{f s}$ is the spring stiffness of the variable inertia flywheel, $I_{\min }$ denotes the free length of the spring, $c_{\theta}$ is the combined viscous damping co-efficient for loss at the bearings and viscous drag on the flywheel, $c_{\text {line }}$ is the coefficent of line resistance of the circuit and $c_{l}$ is the viscous damping between the slider and the slot. The radial and tangential components of acceleration of the ith slider are $a_{r}=\ddot{l}_{i}-l_{i} \dot{\theta}^{2}$ and $a_{\theta}=2 \dot{l}_{i} \dot{\theta}+l_{i} \ddot{\theta}$, respectively. The normal reaction on the slot from the slider is $m_{s} a_{\theta}$ and this reaction gives a part of the load torque.

The Lagrange's equations of motion in generalized coordinates are given as [29-32]

$\frac{d}{d t}\left(\frac{\partial L}{\partial \dot{l}_{i}}\right)-\frac{\partial L}{\partial l_{i}}+\frac{\partial D}{\partial \dot{l}_{i}}=F_{c i}, i=1 \ldots 4 ;$

$\frac{d}{d t}\left(\frac{\partial L}{\partial \dot{\theta}}\right)-\frac{\partial L}{\partial \theta}+\frac{\partial D}{\partial \dot{\theta}}=T_{m}-T_{l}$

where $T_{m}=D_{m}\left(P_{m i}-P_{m o}\right)$ is the torque produced by the hydro-motor, $T_{I}=D_{p}\left(P_{\text {lup }}-P_{\text {ldn }}\right)$ is load from loading system, $P_{\text {lup }}$ and $P_{\text {Idn }}$ are the pressures in the loading system (see Fig. 1), $D_{p}$ is load pump's volume displacement rate, and $F_{c i}$ is the constraint force on ith slider. The constraint force results from exceeding the limits of piston travel, i.e. when $I>I_{\max }$ or $I<I_{\min }$. It may be written explicitly by using Lagrange multipliers. However, here it is implemented implicitly by assuming contact of piston with hard stops. Thus, $F_{c i}=-\left(k_{s t}\left(I_{i}-I_{\max }\right)+c_{s t} \dot{I}_{i}\right) \mathrm{H}\left(I_{i}-I_{\max }\right)+\left(k_{s t}\left(I_{i}-I_{\min }\right)\right.$ $\left.+c_{s t} I_{i}\right) \mathrm{H}\left(I_{\min }-I_{i}\right)$ where $\mathrm{H}($.$) is the Heaviside function, and$ 
$k_{s t}$ and $c_{s t}$ are the high stiffness and damping, respectively, at the metal to metal contact.

For the considered system, the simplified forms of Eqs. (13) and (14) are expressed as

$$
\begin{aligned}
& m_{s} \ddot{I}_{i}-m_{s} l_{i} \dot{\theta}^{2}+k_{f s}\left(I-I_{\min }\right)+c_{l} \dot{l}_{i} \\
& \quad+\left(k_{s t}\left(I_{i}-I_{\max }\right)+c_{s t} \dot{I}_{i}\right) \mathrm{H}\left(I_{i}-I_{\max }\right) \\
& \quad-\left(k_{s t}\left(I_{i}-I_{\min }\right)+c_{s t} I_{i}\right) \mathrm{H}\left(I_{\min }-I_{i}\right) \\
& \quad=0, i=1 \ldots 4 ; \\
& \left(J_{f}+4 J_{s}\right) \ddot{\theta}+m_{s} \sum_{i=1}^{4} I_{i}^{2} \ddot{\theta}+2 m_{s} \sum_{i=1}^{4} I_{i} i_{i} \dot{\theta}+c_{\theta} \dot{\theta} \\
& \quad+c_{\text {line }} \dot{\theta}=D_{m}\left(P_{m i}-P_{m o}\right) .
\end{aligned}
$$

Note that for the VIF, Eq. (16) replaces Eq. (6), which was written for constant inertia flywheel. Equations (6) and (16) are equivalent when $m_{s}=0$.

\subsection{Modeling of soft switch}

The soft switch absorbs any unbalanced thrust force on its piston during the transition of the $4 / 2$ direction control valve from normal to cross port and vice versa (refer Fig. 1). Effectively, the soft switch acts as a second-order low-pass filter which can be tuned to adjust the time constant and the overshoot. A schematic diagram of the soft switch is shown in Fig. 4. During the valve transition, the high-pressure throttle fluid pushes the piston towards the tail end of the soft switch. After enough piston travel, the piston annulus and the internal port of the soft switch coincide and the fluid is passed through the internal port to the tank. The spring force tries to push the piston back to its position. Simultaneously, the flow is passed through the check valve from the tank to the tail end of the soft switch to avoid the cavitations and the piston returns to its initial position. Another check valve at safety line is used for safety purpose, especially to prevent piston seizure.

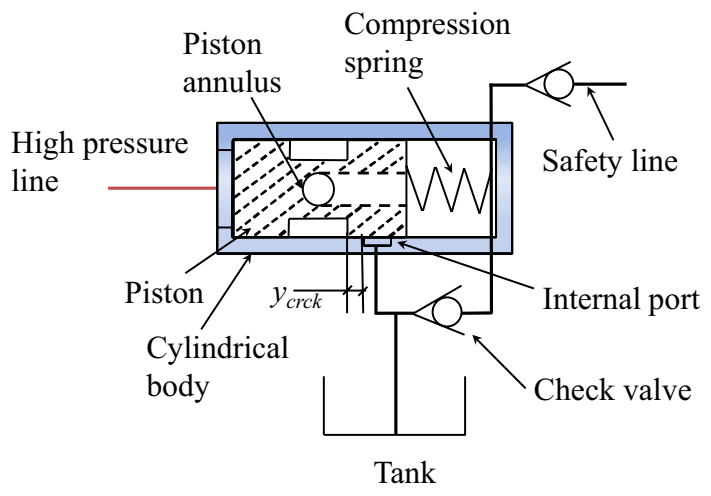

Fig. 4 Schematic diagram of the soft switch
The equations of motions of the soft switch piston is expressed as

$$
m_{s s} \ddot{y}_{s s}=\left(P_{s}-P_{s t}\right) A_{s s}-F_{p l s p}-k_{s p} y_{s s}-\left(\frac{\pi \mu_{0} d_{s s} l_{s s}}{\delta_{s s}}\right) \dot{y}_{s s}
$$

where $m_{s s}$ and $y_{s s}$ are the mass and displacement of the piston, respectively, $v_{s s}=\dot{y}_{s s}$ is the corresponding velocity, $P_{s}, P_{s t}$ and $A_{s s}=\pi d_{s s}^{2} / 4$ are the plenum pressure, soft switch back chamber pressure and the effective surface area of the piston, respectively, $F_{p l s p}, k_{s p}, \mu_{0}, d_{s s}, l_{s s}$ and $\delta_{s s}$ are preload force in the spring, spring stiffness, oil viscosity, diameter of the soft switch piston, length of the piston and diametrical clearance of the piston, respectively.

The pressure at the tail end (back chamber) of the soft switch is expressed as

$\dot{P}_{s t}=\frac{B_{e f}\left(P_{s t}\right)}{V_{s s c}+A_{s s}\left(y_{s s \max }-y_{s s}\right)}\left(A_{s s} v_{s s}-Q_{t c h v}-Q_{s c h v}-Q_{s s p r t}\right)$.

where $V_{s s c}$ and $y_{s s m a x}$ are the clearance volume at the tail end of soft switch and maximum possible travel distance of the soft switch, respectively, and $Q_{\text {tchv }}, Q_{\text {schv }}$ and $Q_{\text {ssprt }}$ are the flow through two check valves connecting to tank and pump plenum, and the flow through the internal port respectively. These flows are given as

$Q_{t c h v}= \begin{cases}0 & \text { if } P_{c r c k}>P_{t}-P_{s t} \\ C_{d c h v} A_{c h v} \sqrt{\frac{2\left(P_{t}-P_{s t}-P_{c r k}\right)}{\rho}} & \text { if } P_{c r c k} \leq P_{t}-P_{s t} ;\end{cases}$

$Q_{s c h v}= \begin{cases}0 & \text { if } P_{c r c k}>P_{s t}-P_{m i}, \\ C_{d c h v} A_{c h v} \sqrt{\frac{2\left(P_{s t}-P_{m i}-P_{c r k}\right)}{\rho}} & \text { if } P_{c r c k} \leq P_{s t}-P_{m i} ;\end{cases}$

$Q_{s s p r t}=C_{d p t} A_{p t} \sqrt{\frac{2\left|\left(P_{s t}-P_{t}\right)\right|}{\rho}} \operatorname{sign}\left(P_{s t}-P_{t}\right)$.

In Eqs. (19-21), $C_{d c h v}$ and $A_{c h v}$ are the co-efficient of discharge and orifice area of the check valve, respectively, $P_{c r c k}$ is the cracking pressure of the check valve, $C_{d p t}$ and $A_{p t}$ are the co-efficient of discharge and the area of the internal port of the soft switch, respectively, and sign(.) is the signum function. The cracking pressure $P_{c r c k}$ is the minimum differential upstream pressure between inlet and outlet ports of the check valve. When the system pressure is higher than the cracking pressure, the check valve starts to operate and allows flow through it.

The internal port area of the soft switch is conditioned as 


$$
A_{p t}= \begin{cases}0 & \text { if } y_{s s}<y_{c r c k} \\ \pi d_{s s}\left(y_{s s}-y_{c r c k}\right) & \text { if } y_{c r c k} \leq y_{s s}<y_{c r c k}+l_{p t} \\ \pi d_{s s} l_{p t} & \text { if } y_{s s} \geq y_{c r c k}+l_{p t}\end{cases}
$$

where $I_{p t}$ is the axial length of the internal port and $y_{c r c k}$ is the crack length of the piston travel.

\subsection{Modeling of the loading system}

For initial numerical study, the loading system will be neglected from the model by considering $D_{p}=0$. However, it would be included later to study the effect of variable load. The plenum pressures in the loading pump are determined from

$$
\begin{aligned}
\dot{P}_{\text {lup }} & =\frac{B_{\text {ef }}\left(P_{\text {lup }}\right)}{V_{\text {lup }}} \\
& \left(D_{p} \omega_{f}-P_{\text {lup }} / R_{\text {leak }}-\left(P_{\text {lup }}-P_{\text {ldn }}\right) / R_{\text {il }}+Q_{\text {uchv }}-Q_{\text {urlv }}\right), \\
\dot{P}_{\text {ldn }} & =\frac{B_{\text {ef }}\left(P_{\text {lup }}\right)}{V_{\text {ldn }}} \\
& \left(-D_{p} \omega_{f}-P_{\text {ldn }} / R_{\text {leak }}+\left(P_{\text {lup }}-P_{\text {ldn }}\right) / R_{\text {il }}+Q_{\text {dchv }}-Q_{\text {drlv }}\right),
\end{aligned}
$$

where $P_{\text {lup }}$ and $P_{\text {Idn }}$ are the pressures in the loading system (see Fig. 1), $V_{\text {lup }}=V_{\text {ldn }}=V_{\text {l }}$ is the load pump's equivalent plenum volume, $D_{p}$ is load pump's volume displacement rate, $R_{i l}$ and $R_{\text {leak }}$ are the internal and external leakage resistances as defined for the motor, $Q_{u c h v}$ and $Q_{d c h v}$ are flows through the check valves in the suction lines from the tank, and the $Q_{u r l v}$ and $Q_{d r l v}$ are flows through the load or relief valves. These flows $\left(Q_{u c h v}, Q_{d c h v}, Q_{u r l v}\right.$ and $\left.Q_{d r / v}\right)$ are given as

$Q_{d c h v}= \begin{cases}0 & \text { if } P_{t}-P_{l d n}<0, \\ C_{d d c h v} A_{d c h v} \sqrt{\frac{2\left(P_{t}-P_{l d n}\right)}{\rho}} & \text { if } P_{t}-P_{l d n} \geq 0 ;\end{cases}$

$Q_{u c h v}= \begin{cases}0 & \text { if } P_{t}-P_{\text {lup }}<0, \\ C_{\text {udchv }} A_{\text {uchv }} \sqrt{\frac{2\left(P_{t}-P_{\text {lup }}\right)}{\rho}} & \text { if } P_{t}-P_{\text {lup }} \geq 0 ;\end{cases}$

$Q_{u r l v}= \begin{cases}0 & \text { if } P_{\text {lup }}-P_{t}<P_{\text {set }} ; \\ C_{\text {durlv }} A_{\text {urlv }} \sqrt{\frac{2\left(P_{\text {lup }}-P_{t}-P_{\text {set }}\right)}{\rho}} & \text { if } s P_{\text {lup }}-P_{t} \geq P_{\text {set }} ;\end{cases}$

$Q_{d r l v}= \begin{cases}0 & \text { if } P_{l d n}-P_{t}<P_{\text {set }}, \\ C_{d d r l v} A_{d r l v} \sqrt{\frac{2\left(P_{l d n}-P_{t}-P_{s e t}\right)}{\rho}} & \text { if } P_{l d n}-P_{t} \geq P_{\text {set }} ;\end{cases}$ where $C_{d d c h v}=C_{d u c h v}=C_{d c h v}$ are discharge coefficients of check valves, $A_{d c h v}=A_{u c h v}=A_{c h v}$ are the port areas of open check valves, $C_{d d r l v}=C_{d u r l v}=C_{d r l v}$ are discharge coefficients of relief valves, $A_{d r / v}=A_{u r / v}=A_{r / v}$ are the port areas of open relief valves, and $P_{\text {set }}$ is the set pressure of the pressure relief valve.

\section{Results and discussion}

The parameters used for model simulation are given in Table 1. The parameters related to the hydraulic system and soft switch correspond to the experimentally validated data given in [26]. The performance of the variable inertia flywheel has been validated experimentally in [21] and the parameters used therein are considered in the present study. All the four different models (HST $_{C I F,}$ $\mathrm{HST}_{V I F}, \mathrm{HST}_{\text {CIFSW }}$ and $\mathrm{HST}_{V I F S W}$ ) are simulated and responses of pressures and hydro-motor speeds are compared. Initial simulations are done without loading system which is later introduced in Sect. 5.1. Note that HST $_{C I F}$ is the base model in which constant inertia flywheel is used; there is no inertia variation or soft switch.

When the pump flow is passed through the normal port of the 4/2 DCV, the upstream side pressure is about 3.01 MPa, downstream side pressure is about $0.11 \mathrm{MPa}$ and flywheel rotates with $191.5 \mathrm{rad} \mathrm{s}^{-1}$ speed. After a certain period of the operation (after $11.5 \mathrm{~s}$ ), the valve position is changed to cross-port position and the pressure line is changed accordingly, i.e. the upstream pressure is changed to downstream pressure and vice versa (refer Figs. 5, 6, 7). Also, the flywheel starts to rotate in the reverse direction with the same speed. Again, after $20 \mathrm{~s}$ the valve position is reversed to its normal port position and all the states return to their previous condition. The sudden speed reversal sets up pressure transients or shocks and thus, the primary objective of this research is to study how the added devices (soft switch and/or VIF) absorb those shocks and reduce the energy loss by limiting the vibrations.

It is observed that the steady state responses of all the four systems are identical. The only variation is observed during the transient periods. The pressure surge among all the responses is highest for $\mathrm{HST}_{C I F}$ system and lowest for $\mathrm{HST}_{\text {VIFSW }}$ system. The fluctuations are least when both the soft switch and variable inertia flywheel are used together.

The upstream and downstream side pressures $\left(P_{m i}\right.$ and $P_{m o}$ ) of different configurations are shown in Figs. 5 and 6 , respectively. The maximum value of the pressure surge is about $6.97 \mathrm{MPa}$ in $\mathrm{HST}_{\text {IIF }}$ system and its numerical value has been decreased to $6.69 \mathrm{MPa}$ in HST $_{\text {CIFSW }}$ system. Further, it is reduced to $6.27 \mathrm{MPa}$ for 
Table 1 Parameter values chosen for simulation

\begin{tabular}{|c|c|c|}
\hline Variable & Description & Value \\
\hline$A_{c h v}$ & Orifice area of check valve & $8.2 \times 10^{-6} \mathrm{~m}^{2}$ \\
\hline$A_{r l v}$ & Port area of relief valve in loading circuit & $6.0 \times 10^{-6} \mathrm{~m}^{2}$ \\
\hline$B$ & Air-free hydraulic fluid bulk modulus at atmospheric pressure & $1.9 \times 10^{8} \mathrm{~N} \mathrm{~m}^{-2}$ \\
\hline$c_{1}$ & Viscous damping in slider of VIF & $1.3 \mathrm{~N} \mathrm{~s} \mathrm{~m}^{-1}$ \\
\hline$c_{\text {line }}$ & Line resistance in hydraulic circuit & $2 \times 10^{-2} \mathrm{~N} \mathrm{~m} \mathrm{~s} \mathrm{rad}{ }^{-1}$ \\
\hline$c_{s t}$ & Metal to metal contact stiffness at stops in VIF & $40 \mathrm{~N} \mathrm{~s} \mathrm{~m}^{-1}$ \\
\hline$c_{\theta}$ & Viscous resistance on the flywheel (including bearings) & $1.6 \times 10^{-5} \mathrm{~N} \mathrm{~m} \mathrm{~s} \mathrm{rad}^{-1}$ \\
\hline$C_{\mathrm{d}}$ & Coefficient of discharge of $4 / 2$ DCV & 0.9 \\
\hline$C_{d c h v}$ & Coefficient of discharge of check valve & 0.9 \\
\hline$C_{d p t}$ & Coefficient of discharge of internal port of the soft switch & 0.9 \\
\hline$C_{d r l v}$ & Coefficient of discharge of relief valve in loading circuit & 0.6 \\
\hline$d_{s}$ & Diameter of the slider in VIF & $0.02 \mathrm{~m}$ \\
\hline$d_{s s}$ & Diameter of the soft switch piston & $9 \times 10^{-3} \mathrm{~m}$ \\
\hline$D_{m}$ & Volume displacement rate of the hydro-motor & $1.31 \times 10^{-6} \mathrm{~m}^{3} \mathrm{rad}^{-1}$ \\
\hline$D_{p}$ & Volume displacement rate of the loading pump & $1.00745 \times 10^{-6} \mathrm{~m}^{3} \mathrm{rad}^{-1}$ \\
\hline$F_{p l s p}$ & Preload force of compression spring in soft switch & $170 \mathrm{~N}$ \\
\hline$J_{f}$ & Constant inertia of the flywheel & $1 \times 10^{-3} \mathrm{~kg} \mathrm{~m}^{2}$ \\
\hline$J_{\text {shaft }}$ & Inertia of fixed part of shaft & $1 \times 10^{-4} \mathrm{~kg} \mathrm{~m}^{2}$ \\
\hline$k_{f s}$ & Spring stiffness of the flywheel spring in VIF & $4990 \mathrm{~N} \mathrm{~m}^{-1}$ \\
\hline$k_{s p}$ & Compression spring stiffness in soft switch & $2 \times 10^{4} \mathrm{~N} \mathrm{~m}^{-1}$ \\
\hline$k_{s t}$ & Metal to metal contact stiffness at stops in VIF & $10^{6} \mathrm{~N} \mathrm{~m}^{-1}$ \\
\hline$I_{\min }$ & Minimum position of VIF slider & $0.0225 \mathrm{~m}$ \\
\hline$I_{\max }$ & Maximum position of VIF slider & $0.0375 \mathrm{~m}$ \\
\hline$I_{p t}$ & Axial length of the internal port in soft switch & $0.008 \mathrm{~m}$ \\
\hline$I_{s}$ & Length of the slider in VIF & $0.015 \mathrm{~m}$ \\
\hline$I_{\text {slot }}$ & Length of the slot in VIF & $0.03 \mathrm{~m}$ \\
\hline$I_{s s}$ & Length of the piston in soft switch & $13 \times 10^{-3} \mathrm{~m}$ \\
\hline$m_{s}$ & Mass of the VIF slider & $0.035 \mathrm{~kg}$ \\
\hline$m_{s c d}$ & Mass of flywheel in VIF if slots were absent & $1.066 \mathrm{~kg}$ \\
\hline$m_{\text {slot }}$ & Mass of the removed material from each slot of the VIF circular disk & $0.079 \mathrm{~kg}$ \\
\hline$m_{s s}$ & Mass of soft switch piston & $0.007 \mathrm{~kg}$ \\
\hline$P_{\text {crck }}$ & Check valve crack pressure in soft switch & $55 \mathrm{kPa}$ \\
\hline$P_{0}$ & Atmospheric pressure & $10^{5} \mathrm{~m}$ \\
\hline$Q_{\text {pump }}$ & Pump flow & $25 \times 10^{-5} \mathrm{~m}^{3} \mathrm{~s}^{-1}$ \\
\hline$r_{i}$ & Inner radius of circular disk in VIF & $0.01 \mathrm{~m}$ \\
\hline$r_{0}$ & Outer radius of the circular disk in VIF & $0.047 \mathrm{~m}$ \\
\hline$R_{i l}$ & Internal leakage resistance in motor & $17 \times 10^{18} \mathrm{~N} \mathrm{~s} \mathrm{~m}^{-5}$ \\
\hline$R_{\text {leak }}$ & External leakage resistance in motor & $6.5 \times 10^{18} \mathrm{~N} \mathrm{~s} \mathrm{~m}^{-5}$ \\
\hline$t_{d}$ & Time delay for valve transition & $1 \mathrm{~ms}$ \\
\hline$V_{l}$ & Volume of loading plenum fluid & $4.8 \times 10^{-4} \mathrm{~m}^{3}$ \\
\hline$V_{m}$ & Volume of motor plenum fluid & $4.8 \times 10^{-4} \mathrm{~m}^{3}$ \\
\hline$V_{s s c}$ & Clearance volume at the tail end of sift switch & $10 \times 10^{-6} \mathrm{~m}^{3}$ \\
\hline$V_{s w}$ & Switched volume & $1 \times 10^{-6} \mathrm{~m}^{3}$ \\
\hline$y_{\text {crck }}$ & Crack travel length in soft switch & $7 \times 10^{-3} \mathrm{~m}$ \\
\hline$y_{s s \max }$ & Maximum allowable piston travel distance in soft switch & $17.5 \times 10^{-3} \mathrm{~m}$ \\
\hline$\delta_{s s}$ & Diametric clearance of the piston in soft switch & $0.4 \times 10^{-6} \mathrm{~m}$ \\
\hline$\mu_{0}$ & Dynamic viscosity & $1 \mathrm{Ns} \mathrm{m}^{-2}$ \\
\hline
\end{tabular}

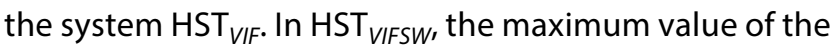
pressure surge is almost same as the system $\mathrm{HST}_{V I F}$ and it is 6.25 MPa. Therefore, when the soft switch and the variable inertia flywheel are used simultaneously, the 


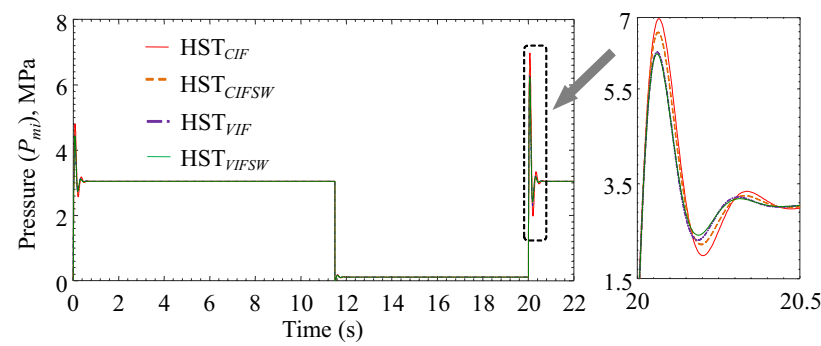

Fig. 5 Upstream side pressure versus time

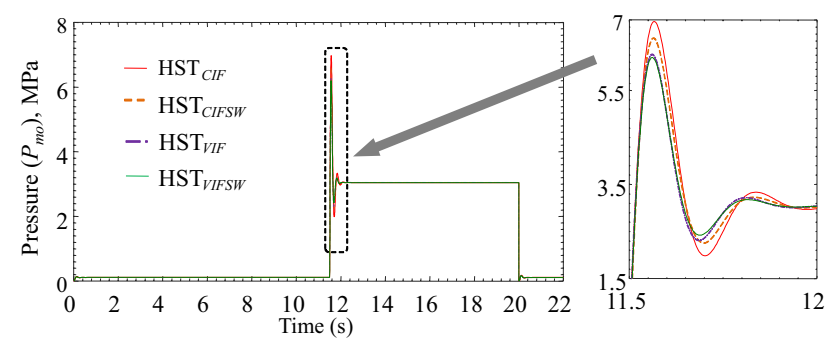

Fig. 6 Downstream side pressure versus time

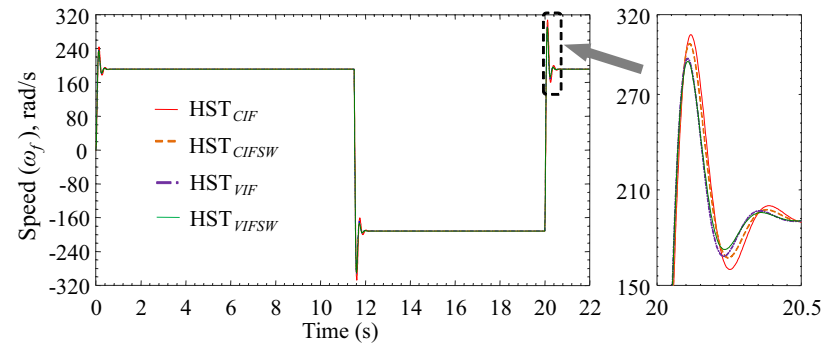

Fig. 7 Speed of the flywheel versus time

maximum value of the pressure surge does not reduce as compared to use of only the variable inertia flywheel. However, it would be shown later that there using both the devices together increases the energy efficiency; in fact the VIF does not reduce throttling energy loss at all and all the energy saving comes from the soft switch alone.

The corresponding peak value of the flywheel speed during the valve transition is maximum ( $\omega_{f}$ is $307 \mathrm{rad} \mathrm{s}^{-1}$ ) in $\mathrm{HST}_{C I F}$ system as shown in Fig. 7. The lowest peak value of the flywheel speed is observed in $\mathrm{HST}_{\text {VIFSW }}$ system and it is about $290 \mathrm{rad} \mathrm{s}^{-1}$. In case of the other two systems, the peak values are $301 \mathrm{rad} \mathrm{s}^{-1}$ and $292.5 \mathrm{rad} \mathrm{s}^{-1}$ in HST CIFSW $_{\text {in }}$ and $\mathrm{HST}_{V I F}$, respectively. Therefore, the peak value of the

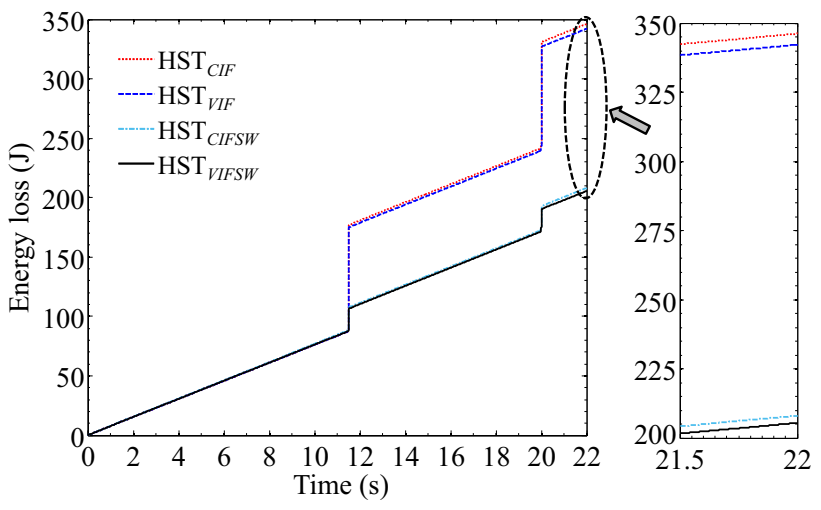

Fig. 8 Throttling energy loss of four different systems

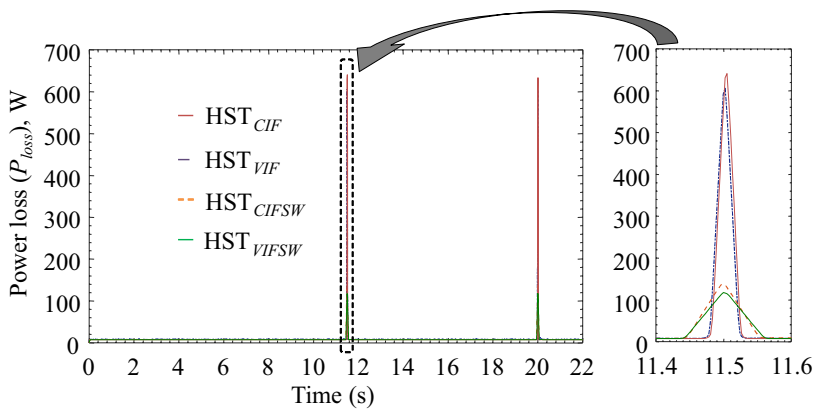

Fig. 9 Throttling power loss of four different systems

flywheel speed decreases by using soft switch and VIF, either individually or together; and hence, the system vibration reduces. However, the degree of vibration control achieved by the soft switch and the VIF is not clearly understood at this point. To investigate further, the throttling energy loss and throttling power loss of all four systems are studied (refer Figs. 8, 9).

When the control valve is in transition period, it dissipates energy which is termed as throttling energy loss [23-25] and it is associated with loss of pressure head through the DCV. An amount of power is required to overcome the head loss of the valve and is estimated as a product of pressure drop across the valve port $(\Delta P)$ and the flow rate $(Q)$ through it. The throttling energy loss is the integration of the throttling power loss of the system. The power loss $\left(P_{\text {loss }}\right)$ and the energy loss $\left(E_{\text {loss }}\right)$ during the throttling of the DCV are, respectively, given as

$P_{\text {loss }}=(\Delta P . Q)_{\text {nport }}+(\Delta P . Q)_{\text {cport }}$

$E_{\text {loss }}=\int P_{\text {tloss }} d t$ 
The throttling energy losses of all four systems are plotted in Fig. 8. It is observed that the throttling energy loss of the system is reduced from 347 to $203 \mathrm{~J}$ when only the soft switch is incorporated into the system. The throttling energy loss is almost unchanged when variable inertia flywheel is into the system in place of constant inertia flywheel, without incorporating the soft switch $\left(\mathrm{HST}_{\mathrm{CIF}}=347 \mathrm{~J}\right.$ and $\mathrm{HST}_{V I F}=341 \mathrm{~J}$ ). Therefore, the variable inertia flywheel does not contribute towards reduction of the throttling energy loss. On the other hand, it reduces the pressure transients and vibration of the system whereas the soft switch reduces the throttling energy loss.

The throttling power losses of all the systems are shown in Fig. 9. The throttling power loss is similar in all the four systems during steady state. However, a significant change is observed during the valve transition, i.e. the transient period. The throttling power loss is highest $(640 \mathrm{~W})$ in $\mathrm{HST}_{\text {CIF }}$ and lowest in $\mathrm{HST}_{\text {VIFSW }}(120 \mathrm{~W})$. In the other two systems, the throttling power loss is intermediate (i.e. $\mathrm{HST}_{V I F}=610 \mathrm{~W}, \mathrm{HST}_{S W}=144 \mathrm{~W}$ ).

\section{Influence of different system parameters}

The results presented in Sect. 4 consider the inertial load of the constant and variable inertia flywheel. A major part of the load torque occurs due to acceleration and deceleration of the flywheel, and a small part is present due to Coriolis forces and viscous damping, as described by the left side of Eq. (16). However, in practice, some useful work is extracted out of the system in the form of additional load. The load can be a complicated driven system such as an oscillating slider-crank mechanism, a gear train driving a wheel, a power steering, a hydraulic jack or hydraulic press, a robot arm, a compressor, excavator or other earth moving equipment, a boom crane, and other such hydraulically actuated systems. These loads are generally represented as a generic loading circuit, such as in Fig. 1, during design of hydraulic control system.

\subsection{Influence of the loading unit on different configurations of the hydraulic system}

The influence of the loading unit on the different configurations of the hydraulic system such as $\mathrm{HST}_{C I F}, \mathrm{HST}_{V I F}$ HST $_{\text {CIFSW }}$ and HST VIFSW $_{\text {are analyzed in this section. The }}$ loading unit consists of a radial piston pump and two relief valves $[26,27]$. When the flywheel rotates in clockwise

(a)

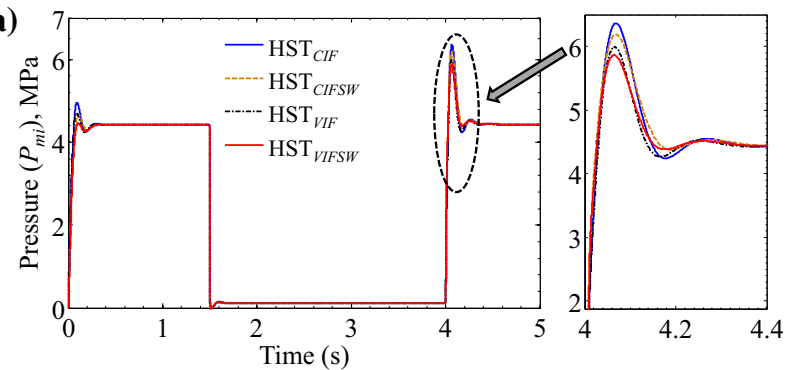

(b)

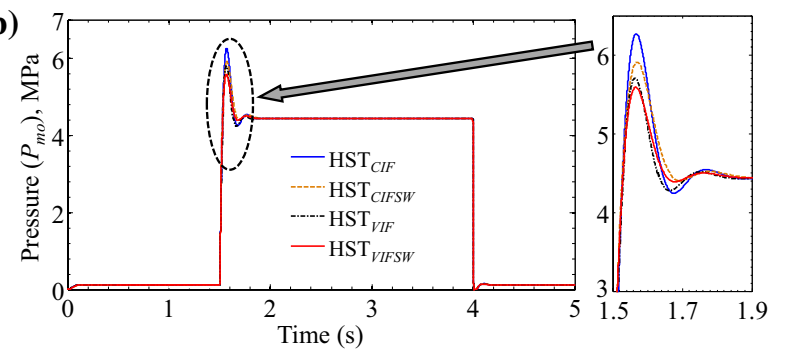

Fig. 10 Pressure responses whenever the load pressure is $0.6 \mathrm{Mpa}$ : a $P_{m i}$ and $\mathbf{b} P_{m o}$

Table 2 Comparative performance analysis in various loading conditions

\begin{tabular}{llllllllll}
\hline Set pressure (MPa) & $\begin{array}{l}\text { System con- } \\
\text { figuration }\end{array}$ & $P_{\text {mi }}(\mathrm{MPa})$ & $P_{\text {mo }}(\mathrm{MPa})$ & $\omega_{f}\left(\mathrm{rad} \mathrm{s}^{-1}\right)$ & $P_{\text {lup }}(\mathrm{MPa})$ & $P_{\text {ldn }}(\mathrm{MPa})$ & $Q_{\text {urlv }}\left(\mathrm{m}^{3} \mathrm{~s}^{-1}\right)$ & $Q_{\text {drlv }}\left(\mathrm{m}^{3} \mathrm{~s}^{-1}\right)$ & $E_{\text {loss }}(\mathrm{J})$ \\
\hline$P_{\text {set }}=0.6$ & $\mathrm{HST}_{\text {CIF }}$ & 6.36 & 6.26 & \pm 252 & 2.37 & 2.33 & $2.21 \times 10^{-4}$ & $2.19 \times 10^{-4}$ & 216 \\
& $\mathrm{HST}_{\text {CIFSW }}$ & 6.19 & 5.91 & \pm 251 & 2.37 & 2.29 & $2.21 \times 10^{-4}$ & $2.17 \times 10^{-4}$ & 63.9 \\
& $\mathrm{HST}_{\text {VIF }}$ & 5.99 & 5.88 & \pm 245 & 2.33 & 2.20 & $2.15 \times 10^{-4}$ & $2.13 \times 10^{-4}$ & 215.8 \\
& $\mathrm{HST}_{\text {VIFSW }}$ & 5.84 & 5.59 & \pm 242 & 2.25 & 2.16 & $2.15 \times 10^{-4}$ & $2.11 \times 10^{-4}$ & 63.8 \\
& $\mathrm{HST}_{\text {CIF }}$ & 6.42 & 6.27 & \pm 253 & 2.4 & 2.35 & $2.22 \times 10^{-4}$ & $2.20 \times 10^{-4}$ & 216 \\
$P_{\text {set }}=0.8$ & $\mathrm{HST}_{\text {CIFSW }}$ & 6.24 & 5.91 & \pm 250 & 2.4 & 2.3 & $2.23 \times 10^{-4}$ & $2.18 \times 10^{-4}$ & 63.9 \\
& $\mathrm{HST}_{\text {VIF }}$ & 6.05 & 5.89 & \pm 246 & 2.27 & 2.21 & $2.14 \times 10^{-4}$ & $2.13 \times 10^{-4}$ & 215.8 \\
& $\mathrm{HST}_{\text {VIFSW }}$ & 5.92 & 5.59 & \pm 244 & 2.27 & 2.17 & $2.17 \times 10^{-4}$ & $2.12 \times 10^{-4}$ & 63.84 \\
& $\mathrm{HST}_{\text {CIF }}$ & 6.48 & 6.28 & \pm 254 & 2.4 & 2.36 & $2.24 \times 10^{-4}$ & $2.21 \times 10^{-4}$ & 216 \\
$P_{\text {set }}=1.0$ & $\mathrm{HST}_{\text {CIFSW }}$ & 6.29 & 5.92 & \pm 251 & 2.43 & 2.31 & $2.24 \times 10^{-4}$ & $2.18 \times 10^{-4}$ & 63.9 \\
& $\mathrm{HST}_{\text {VIF }}$ & 6.12 & 5.98 & \pm 247 & 2.3 & 2.22 & $2.18 \times 10^{-4}$ & $2.14 \times 10^{-4}$ & 215.8 \\
& $\mathrm{HST}_{\text {VIFSW }}$ & 5.97 & 5.6 & \pm 244 & 2.3 & 2.18 & $2.18 \times 10^{-4}$ & $2.12 \times 10^{-4}$ & 63.85 \\
\hline
\end{tabular}


Table 3 Comparative performance analysis on various $k_{f s}$ and $m_{s}$

\begin{tabular}{llllllll}
\hline $\begin{array}{l}\text { Varying param- } \\
\text { eter (others } \\
\text { fixed) }\end{array}$ & Nominal value & Varied value & $\begin{array}{l}P_{m i} \\
(\mathrm{MPa})\end{array}$ & $P_{m o}(\mathrm{MPa})$ & $\omega_{f}\left(\mathrm{rad} \mathrm{s}^{-1}\right)$ & $I(\mathrm{~m})$ & $E_{\text {loss }}(\mathrm{J})$ \\
\hline$k_{f s}$ & $4990 \mathrm{~N} \mathrm{~m}^{-1}$ & $4490 \mathrm{~N} \mathrm{~m}^{-1}$ & 5.862 & 5.626 & \pm 244 & 0.037 & 64.45 \\
& & $4990 \mathrm{~N} \mathrm{~m}^{-1}$ & 5.839 & 5.604 & \pm 242 & 0.037 & 64.48 \\
& & $5490 \mathrm{~N} \mathrm{~m}^{-1}$ & 5.822 & 5.587 & \pm 237 & 0.035 & 64.50 \\
$m_{s}$ & $0.035 \mathrm{~kg}$ & $0.025 \mathrm{~kg}$ & 5.711 & 5.477 & \pm 238 & 0.031 & 64.57 \\
& & $0.035 \mathrm{~kg}^{2}$ & 5.839 & 5.604 & \pm 242 & 0.037 & 64.48 \\
& & $0.045 \mathrm{~kg}^{2}$ & 6.012 & 5.774 & \pm 247 & 0.037 & 64.34 \\
\hline
\end{tabular}

direction, the loading pump supplies flow to the tank through one pressure relief valve (PRV). A pressure variation can be generated in the loading unit by varying the set pressure $\left(P_{\text {set }}\right)$ of the relief valve. Similarly, the operation is repeated whenever the flywheel rotates in counterclockwise direction, but in that case the loading pump supplies flow to the tank through the second relief valve. Both relief valves are alternatively used for clockwise and counter-clockwise rotations of the flywheel. The value of $P_{\text {set }}$, i.e. the set pressure of the relief valve, is varied here in three steps: $0.6 \mathrm{MPa}, 0.8 \mathrm{MPa}$ and $1.0 \mathrm{MPa}$. The corresponding peak fluctuation values of $P_{m i}, P_{m 0^{\prime}} \omega_{f}, P_{l u p^{\prime}} P_{I d n}$, $Q_{\text {urlv }}, Q_{d r l v}$ and $E_{\text {loss }}$ are presented in Table 2. As a sample response, the responses of the $P_{m i}$ and $P_{m o}$ for all the four different configurations of the system for $P_{\text {set }}=0.6 \mathrm{MPa}$ are shown in Fig. 10.

It is observed that with the increase in $P_{\text {set }}$, the peak fluctuation values in all the responses increase but their steady state values remain unchanged. Also, the peak fluctuation values of all the responses are highest in the $\mathrm{HST}_{\text {CIF }}$ configuration, which is the base configuration, as compared to the other three configurations. The lowest peak fluctuation values are observed in the HST VIFSW System. The remaining two systems, i.e. HST $_{\text {VIF }}$ and HST CIFSW, provide intermediate peak response values.

\subsection{Influence of spring stiffness and the slider mass of the VIF on the hydraulic system}

The influence on the performance of the hydraulic system (HST VIFSW with the loading unit) with different values of the spring stiffness $\left(k_{f s}\right)$ and mass of the slider $\left(m_{s}\right)$ of the VIF are tabulated in Table 3. The values of parameters $k_{f s}$ and $m_{s}$ are varied individually, while keeping the other parameters fixed. It is observed that with increase of $k_{f s}$, the pressure surge and the speed surge decrease marginally and the peak deflection of the VIF slider reduces, thereby reducing the peak effective inertia. For lower value of $k_{f s}$ it slider reaches its maximum allowable deflection value, i.e. $0.0375 \mathrm{~m}$, as shown in Fig. 11. If the $k_{f s}$ is higher, position of the VIF slider is lower. Similarly, the mass of the slider $m_{s}$ of the VIF is varied in three levels: $0.025 \mathrm{~kg}$, $0.035 \mathrm{~kg}$ and $0.045 \mathrm{~kg}$. It is observed that with increase of $m_{s}$, the pressure and the speed surge both are increased and the VIF slider deflection also increases due to increasing centrifugal force [see the second term in the left side of Eq. (15)]. For $0.045 \mathrm{~kg}$ mass, the peak deflection reaches its maximum allowable value or the extreme position, as shown in Fig. 12. Apparently, higher stiffness and lower mass, i.e. higher natural frequency of vibration of the slider system, is able to better reduce the pressure surge. On the contrary, higher mass and lower stiffness, i.e. lower natural frequency of vibration of the slider system, reduces the energy loss. While the energy saving does not appear to be significant, over many cycles of operation, this small saving accumulates. Therefore, the medium range of parameter

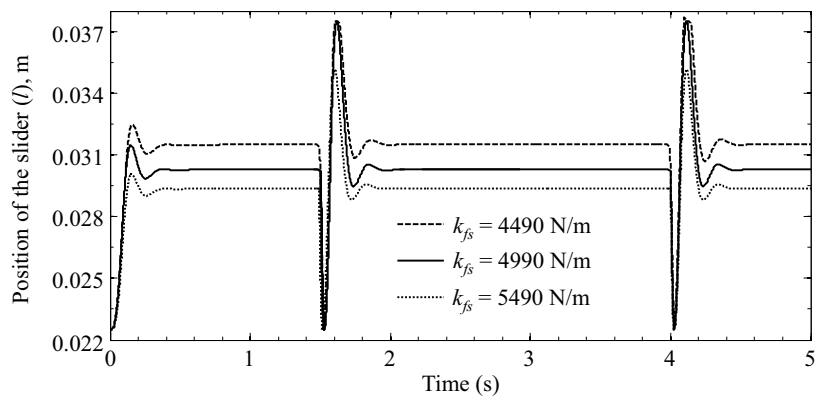

Fig. 11 Positions of the VIF slider with various values of $k_{f s}$ versus time

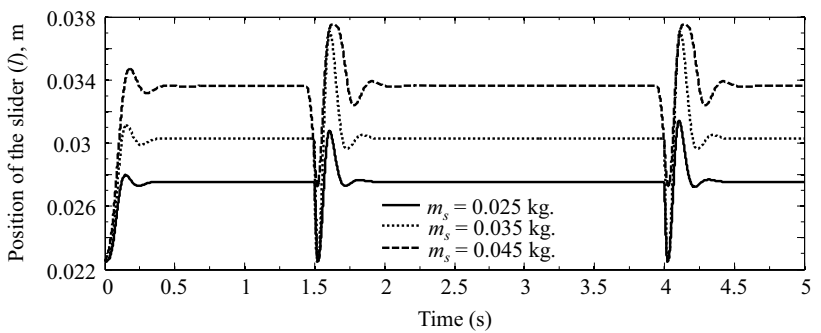

Fig. 12 Positions of the VIF slider with various values of $m_{s}$ versus time 
values is chosen as a trade-off to extract the best performance out of the VIF device.

\section{Conclusions}

This study presents a comparative study between four different configurations of power hydraulic systems, namely a constant inertia flywheel, a variable inertia flywheel and a soft switch, first individually and then together. The steady state responses are same for all the four configurations whereas variations are observed in the transient periods. The pressure surge and speed fluctuations are reduced with the incorporation of variable inertia flywheel and the soft switch in the system. The system vibration and the throttling energy loss are reduced due to the reduction of transition peaks, i.e. the reduction of pressure head of the system. The following key observations are made from the present study:

1. Incorporation of the soft switch or the variable inertia flywheel, or combination of both in the on/off valve controlled power hydraulic system reduces the transition peak of the responses.

2. The value of the transition peak of the responses is lowest when the variable inertia flywheel and the soft switch are used together; whereas the peak attains the highest value when only the constant inertia flywheel is used.

3. The throttling energy loss is reduced due to the incorporation of the soft switch, although it does not contribute significantly towards reduction of the vibration amplitude.

4. The speed fluctuation is reduced due to the incorporation of variable inertia flywheel in comparison to the constant inertia flywheel. However, it does not have significant contribution towards reduction of throttling energy loss.

5. Both the benefits, i.e. energy saving and vibration reduction on an on/off valve controlled power hydraulic system, can be gained by incorporating soft switch and variable inertia flywheel together in the system.

In the present work, only numerical simulations are carried out to investigate the effects of VIF and soft switch in reducing the pressure surge, speed fluctuation and energy loss. The observations made in this study can be validated experimentally. Moreover, the parameters chosen for this study are taken from independent sources which individually dealt with VIF and soft-switch implementations in laboratory-scale experiments. With integration of both the devices together into a common system, the chosen parameters and the design may not be optimal. Thus, optimization of the system parameters may be taken up as a future research activity. Moreover, the damping in the slider is almost negligible. If stick-slip friction conditions are implemented in the slider then the device may act as the so-called nonlinear energy sink (NES). Therefore, NES may be able to dissipate transient vibrations during large acceleration/deceleration, because the radial inertial forces on the slider would cause it to slip under high force and stick under low radial force with the force limit decided by the Coulomb friction law. The Coulomb friction force limit depends on the normal force at the slider-slot contact which results out of the Coriolis and tangential inertial forces on the slider. Thus, the slider system model becomes highly non-linear with coupled dynamics. At the same time, the NES may reduce system efficiency due to dissipation during the slip phase. Therefore, VIF with stick-slip friction between the slider and the slot can be an important area for future research.

\section{Compliance with ethical standards}

Conflict of interest The authors declare that they have no conflict of interest.

\section{References}

1. Li C, Liang M, Wang T (2015) Criterion fusion for spectral segmentation and its application to optimal demodulation of bearing vibration signals. Mech Syst Signal Process 64-65(2015):132-148

2. Richiedei D, Trevisani A, Zanardo G (2011) A constrained convex approach to modal design optimization of vibrating systems. J Mech Des 133(6):061011

3. Spiekermann CE, Radcliffe CJ, Goodman ED (1985) Optimal design and simulation of vibrational isolation systems. J Mech Transmissions Autom Des 107(2):271-276

4. Sun JQ, Jolly MR, Norris MA (1995) Passive, adaptive and active tuned vibration absorbers-a survey. J Mech Des 117(B):234-242

5. Karnopp D (1995) Active and semi-active vibration isolation. J Mech Des 117(B):177-185

6. Simoes RC, Steffen V (2007) Modal active vibration control of a rotor using piezoelectric stack actuators. J Vib Control 13(1):45-64

7. Amer NH, Ramli R, Mahadi W, Liza WN, Abidin Z, Azman M, Rasol Z (2014) Implementations of PID controller and its transient behavior in active suspension system. Adv Mater Res 895(10):490-499

8. Liu Y, Matsuhisa H, Utsuno H (2008) Semi-Active vibration isolation system with variable stiffness and damping control. J Sound Vib 313(1-2):16-28

9. Caruso G, Mekki OB, Bourquin F (2009) Modeling and experimental validation of a new electromechanical damping device. J Vibroeng 11(4):617-626

10. Miljkovic D (2009) Review of active vibration control. In: MIPRO 2009 
11. Weber F, Boston C, Maslanka M (2010) An adaptive tuned mass damper based on the emulation of positive and negative stiffness with an MR damper. Smart Mater Struct 20(1):015012

12. Murudi MM, Mane SM (2004) Seismic effectiveness of tuned mass damper (TMD) for different ground motion parameters. In: 13th World Conference on Earthquake Engineering. Vancouver, Canada, 1-6 August 2004

13. Smith MC, Walker GW (2000) Performance limitations and constraints for active and passive suspensions: a mechanical multiport approach. Veh Syst Dyn 33(3):137-168

14. Smith MC (2002) Synthesis of mechanical networks: the inerter. IEEE Trans Autom Control 47(10):1648-1662

15. Rivin E (2003) Passive vibration isolation. The American Society of Mechanical Engineers, New York

16. Li C, Liang M, Wang Y, Dong Y (2012) Vibration suppression using two-terminal flywheel-part I: modeling and characterization. J Vib Control 18(8):1096-1105

17. Li C, Liang M, Wang Y, Dong Y (2012) Vibration suppression using two-terminal flywheel-part II: application to vehicle passive suspension. J Vib Control 18(9):1353-1365

18. Li C, Liang M (2012) Characterization and modeling of a novel electro-hydraulic variable two-terminal mass device. Smart Mater Struct 21(2):025004

19. Yuan LG, Zeng FM, Xing GX (2010) Research on the design and control strategy of variable inertia flywheel in diesel generator unit under pulsed load. In: International conference on computing, control and industrial engineering (CCIE), Wuhan, China, vol 1, pp 187-189, 5-6 June 2010

20. Jauch C (2015) A flywheel in a wind turbine rotor for inertia control. Wind Energy 18(9):1645-1656

21. Yang S, Xu T, Li C, Liang M (2016) Design, modeling and testing of a two-terminal mass device with a variable inertia flywheel. J Mech Des 138(9):095001
22. Rannow MB, Li PY (2012) Soft switching approach to reducing transition losses in an on/off hydraulic valve. J Dyn Syst Meas Control 134(6):064501

23. Van de Ven JD (2014) Soft switch lock-release mechanism for a switch-mode hydraulic pump circuit. J Dyn Syst Meas Control 136(3):031003

24. Beckstrand BK, Van de Ven JD (2017) Design and validation of a soft switch for a virtually variable displacement pump. J Dyn Syst Meas Control 140(6):061006

25. Mahato AC, Ghoshal SK, Samantaray AK (2017) Influence of locking and passive soft switching on hydraulic circuit efficiency. Simulation 93(3):237-249

26. Mahato AC, Ghoshal SK, Samantaray AK (2017) Energy saving of a hydrostatic drive system by incorporating soft switch. J Braz Soc Mech Sci Eng 39(6):1929-1945

27. Kumar A, Das J, Dasgupta K, Barnwal MK (2018) Effect of hydraulic accumulator on pressure surge of a hydrostatic transmission system. J Inst Eng (India) Ser C 99(2):169-174

28. Gholizadeh $\mathrm{H}$, Burton R, Schoenau G (2012) Fluid bulk modulus: comparison of low pressure models. Int J Fluid Power 13:7-16

29. Thomson TW (2018) Theory of vibration with applications. CRC Press, Boca Raton

30. Irschik H, Holl HJ (2015) Lagrange's equations for open systems, derived via the method of fictitious particles, and written in the Lagrange description of continuum mechanics. Acta Mech 226(1):63-79

31. Morin D (2007) The Lagrangian method. Tillgänglig, Harvard

32. Dienes JK (2001) Crack dynamics via Lagrange's equations and generalized coordinates. Acta Mech 148:79-92. https://doi. org/10.1007/BF01183670

Publisher's Note Springer Nature remains neutral with regard to jurisdictional claims in published maps and institutional affiliations. 